\title{
Does Hearing Aid Use Increase the Likelihood of Cerumen Impaction?
}

\author{
Vinaya Manchaiah ${ }^{1,2,3}$, Jonathan Arthur ${ }^{4,5}$, and Huw Williams ${ }^{6}$ \\ ${ }^{1}$ Department of Speech and Hearing Sciences, Lamar University, Beaumont, TX, USA, \\ ${ }^{2}$ The Swedish Institute for Disability Research, Department of Behavioral Sciences and Learning, Linköping University, Linköping, \\ Sweden, \\ ${ }^{3}$ Audiology India, Mysore, Karnataka, India, \\ ${ }^{4}$ Department of Audiology, ${ }^{6}$ ENT, Cwm Taf University Health Board, Llantrisant, \\ ${ }^{5}$ School of Health and Human Sciences, Swansea University, Singleton Park, Swansea, United Kingdom
}

\section{Received September 11, 2015 \\ Revised October 21, 2015 \\ Accepted November 13, 2015}

Address for correspondence

Vinaya Manchaiah, AuD, MBA, PhD

Department of Speech and

Hearing Sciences, Lamar University,

Beaumont, TX 77710, USA

Tel +1-409-880 8927

Fax +1-409-880 2265

E-mail vinaya.manchaiah@lamar. edu
Background and Objectives: Impacted cerumen is a common condition in adults. It is commonly believed that wearing hearing aids may increase the cerumen impaction, although no empirical evidence exist. The current study was aimed at studying if the use of hearing aids increase the likelihood of impaction of cerumen. Subjects and Methods: The study used retrospective design. The study sample included 164 consecutive patients who were referred to cerumen clinic from Royal Glamorgan Hospital, Wales. Audiologist classified the cerumen impaction into four categories (i.e., no cerumen; non-occluding cerumen; occluding cerumen; and fully non-occluding cerumen and debris). Chi-square analysis was performed to study the association between hearing aid use and cerumen impaction. Results: The current study results showed no association between hearing aid use and cerumen impaction. Also, there was no association between right/left ear and cerumen impaction. Conclusions: These results interesting and contrary to our assumption that hearing aid use increases the likelihood of cerumen impaction. More well-controlled studies with prospective designs are needed to confirm if these results are accurate.

J Audiol Otol 2015;19(3):168-171

KEY WORDS: Impacted cerumen · Ear wax · Hearing loss · Hearing aids.

\section{Introduction}

Cerumen (i.e., ear wax) is defined as a "mixture of secretions (sebum together with secretions from modified apocrine sweat glands) and sloughed epithelial cells, and in a normal substance present in the external auditory canal" [1]. Impacted cerumen is defined as accumulation of cerumen that causes symptoms and may prevent an assessment of external auditory canal including tympanic membrane [2]. It is a common condition and has an incidence in the United Kingdom of around 2.3 million people [3]. Cerumen impaction is reported to be present in approximately 10 percent of children, 7

This is an Open Access article distributed under the terms of the Creative Commons Attribution Non-Commercial License (http://creativecommons. org/licenses/by-nc/3.0/) which permits unrestricted non-commercial use, distribution, and reproduction in any medium, provided the original work is properly cited. percent of normal healthy adults, up to 57 percent of older patients in nursing homes [4]. Often impacted cerumen can cause unpleasant symptoms [5] and sometime it can also be associated with serious consequences such as hearing loss, social withdrawal, poor work function, and perforated eardrum [6].

Cerumen protects the skin in the canal and is naturally extruded [2]. In general, cerumen is a component of the desquamation process, whereby cerumen and other debris, such as epithelial tissue migrates laterally to the external auditory meatus and simply falls out of the ear canal. However, cerumen may accumulate and occlude the canal of one or both ears causing discomfort and other consequences.

It has been postulated that the desquamation process may be compromised causing impaction. Current opinion suggests that anatomically narrow and deformed canals, number of hairs 
in the external auditory canal, and certain dermatological complaints may increase the susceptibility to impaction [2]. It has been suggested that physical barriers to natural wax extrusion including wearing hearing aids, using cotton buds and earplug-type hearing protectors may increase the likelihood of cerumen impaction [7-9]. It is also a common belief in audiology practitioners that wearing hearing aid increases cerumen impaction. Moreover, this information gest discussed in most hearing aid rehabilitation counselling sessions. However, we are unable to find any empirical study that supports this assumption.

Based on these observations we hypothesise that the use of hearing aids will increase the impaction of cerumen. Consequently, this formed the basis of the current study objective.

\section{Subjects and Methods}

\section{Participants}

The study sample included 164 consecutive patients who were referred to cerumen clinic from Audiology Department, Royal Glamorgan Hospital, Cwm Taf Health Board, Rhondda Cynon Taff, Wales. Ethical approval was obtained from Cwm Taf University Health Board, Wales (Approval No: CT/325/13). Generally, as the National Health Services is the biggest provider of healthcare services with over $90 \%$ market share, it is very unlikely if they had consulted other professionals for wax removal. However, we are unsure if the participants had cleaned their ears before visiting the clinic.

\section{Data collection}

In this study four audiologists (1 male; 3 females) were in- volved in cerumen classification and collecting the data. Table 1 provide demographic details of the audiologists.

The cerumen "pathway" was developed in 2008 and the audiologists were trained under supervision of the ENT consultant. Microscopic examination with suction was used and audiologists completed a clinic proforma after examination of the cerumen. The proforma consisted of demographic information of the subject (e.g., age, gender, hearing aid use) and additional factors related to classifying cerumen. This information was recorded as a precautionary measure in case of minor trauma to the ear canal. Audiologists categorized the cerumen impaction into four types. Table 2 provide information about the classification used. The classification of the cerumen was agreed at the start of the process (i.e., prior to seeing the subjects) and there was a clear understanding and agreement by the audiologists and the ENT consultant of the cerumen classification process. In ambiguous cases, there was a discussion over the most suitable classification regarding the cerumen category.

\section{Data analysis}

A chi-square test was used to analyse the categorical data with an alpha level of 0.05 to determine the statistical significance.

\section{Results}

In a sample of 164 subjects, $73(44.5 \%)$ had cerumen in a single ear and the remaining $91(55.5 \%)$ subjects patients had cerumen in both ears resulting in a total number of 255 ears with cerumen (Table 3 ). For subjects with bilateral ceru-

Table 1. Demographic details of audiologists involved in cerumen classification

\begin{tabular}{|c|c|c|c|c|}
\hline SL no. & Gender & Age in years & $\begin{array}{c}\text { No. of years } \\
\text { of experience as audiologist }\end{array}$ & Education (highest degree)/training route \\
\hline 1 & Male & 40 & 22 & M.Sc Audiology \\
\hline 2 & Female & 39 & 21 & $\begin{array}{l}\text { Higher National Certificate of medical physics and physiological } \\
\text { measurement; \& training in the job }\end{array}$ \\
\hline 3 & Female & 57 & 19 & National Certificate; \& training in the job \\
\hline 4 & Female & 54 & 17 & Training in the job \\
\hline
\end{tabular}

Table 2. Cerumen classification

\begin{tabular}{lc}
\hline Classification & Descreption \\
\hline Type 1: no cerumen & $\begin{array}{c}\text { No soft or hard wax seen and complete tympanic membrane can be visualized } \\
\text { during otoscope examination. } \\
\text { Type 2: non-occluding cerumen }\end{array}$ \\
$\begin{array}{c}\text { Otoscope examinations shows some soft and/or hard wax. However, wax is } \\
\text { non-occluding and two third of the tympanic membrane can be visualised. } \\
\text { Otoscope examinations shows occluding soft and/or hard wax, with very little } \\
\text { or no visualization of tympanic membrane. However, some gap can be seen } \\
\text { between ear wax and ear canal wall. }\end{array}$ \\
$\begin{array}{c}\text { Ear canal completely blocked with soft or hard wax and also with debris. No } \\
\text { visualization of tympanic membrane. }\end{array}$ \\
\hline
\end{tabular}


Table 3. Demographic details

\begin{tabular}{ll}
\hline Age (in years) mean \pm SD & $82.72 \pm 10.9$ \\
Gender & 100 male \\
& 64 female \\
Unilateral or bilateral cerumen in 164 patients & 73 unilateral \\
& 91 bilateral \\
Ear with cerumen in 255 ears & 127 right ear \\
& 128 left ear \\
Ear with hearing aid use in 255 ears & 190 ears with hearing aid use ( 97 in right ear and 93 in left ear) \\
Ear with cerumen in 164 ears & 65 ears with no hearing aid use \\
& 81 right ear \\
Ear with hearing aid use in 164 ears & 83 left ear \\
& 117 ears with hearing aid use (60 in right ear and 57 in left ear) \\
\end{tabular}

Table 4. Chi-square results

\begin{tabular}{lcccc}
\hline Factors & $\mathrm{n}$ & Degree of freedom $(\mathrm{df})$ & Chi-square $\left(\chi^{2}\right)$ & Significance $p$ \\
\hline Hearing aid use vs. cerumen impaction & 164 & 8 & 3.55 & 0.89 \\
Right/left ear vs. cerumen impaction & 164 & 4 & 2.55 & 0.63 \\
\hline
\end{tabular}

men, the cerumen category was same in both ears in 86 subjects $(94.5 \%)$. Hence, we felt that the data would be skewed if we included the bilateral cerumen subjects as two separate ears. Therefore, one ear data (i.e., right or left ear irrespective of hearing aid use) was chosen randomly to be included in the analysis. This resulted in a sample of 164 ears in 164 patients (i.e., only one ear data in each patient).

The chi-square analysis in a sample of 164 ears (i.e., with or without hearing aid use) and cerumen impaction category (i.e., no cerumen, non-occluding cerumen, occluding cerumen, or occluding cerumen and debris) as variables showed no association (Table 4). It is important to note that in unilateral hearing aid fitting in bilateral hearing loss patients the choice of side of hearing fitting may be based on the handedness and the right/left ear may have some bias. However, in our sample there was equal spread of right and left ears with cerumen (i.e., 81 right and 83 left ears-which equates to $49.4 \%$ and $50.6 \%$ respectively). Also, chi-square analysis showed no association between right/left ear and cerumen impaction (Table 4). These results suggest that there is no relationship between hearing aid use and increased cerumen impaction.

\section{Discussion}

The current study was aimed at studying if the use of hearing aids increase the likelihood of impaction of cerumen. Study results suggest no association between hearing aid use and cerumen impaction. This is contrary to general assumption that wearing hearing aids increase the chances of cerumen impaction [8,9].
Cerumen management is an important component of medical professionals practice including otolaryngologists. However, general practitioners are becoming more reluctant to offer cerumen management techniques such as syringing as it is associated with clinically significant complications [10]. For this reason, over the last decade cerumen management has become a part of audiologists extended scope of practice in many countries including UK and USA [11]. Now a days audiologists provide information about self-management of cerumen (e.g., ear drops) and in many places trained audiologist are involved in cerumen removal using microscopic techniques. Despite this almost all audiologists talk about ear hygiene during hearing aid rehabilitation sessions. As the evidence-based practice has become an important component of healthcare practice it is important to provide patients with accurate information based on the evidence. Hence, the current study results may be useful for otolaryngologists and audiologists especially for counselling purpose.

\section{Strengths and limitations}

This is the first empirical study (as known by authors), which looks into association between hearing aid use and cerumen impaction. Hence, the study results are important in the field of otology and audiology. The study employed a retrospective design, which is the major limitations of the study. It is likely that some individuals may have cleaned their ears before visiting the audiology department. Moreover, the participant's ear mould type may influence the cerum migration.

These information may have some bearing towards study results, although these information were not collated. 


\section{Conclusion}

Despite the limitations of retrospective data (e.g., not accounting for ear mould type), we find these results interesting and contrary to our assumption that hearing aid use increases the likelihood of cerumen impaction. We suggest that this is an interesting and clinically useful area of study and needs further prospective and well-controlled studies to confirm if these results are accurate.

\section{REFERENCES}

1) Roland PS, Smith TL, Schwartz SR, Rosenfeld RM, Ballachanda B, Earll JM, et al. Clinical practice guideline: cerumen impaction. Otolaryngol Head Neck Surg 2008;139(3 Suppl 2):S1-21.

2) McCarter DF, Courtney AU, Pollart SM. Cerumen impaction. Am Fam Physician 2007;75:1523-8.

3) Guest JF, Greener MJ, Robinson AC, Smith AF. Impacted cerumen: composition, production, epidemiology and management. QJM 2004;97:477-88.

4) Roeser RJ, Ballachanda BB. Physiology, pathophysiology, and anthropology/epidemiology of human earcanal secretions. J Am Acad Audiol 1997;8:391-400.

5) Burkhart CN, Kruge MA, Burkhart CG, Black C. Cerumen composition by flash pyrolysis-gas chromatography/mass spectrometry. Otol Neurotol 2001;22:715-22.

6) Grossan M. Safe, effective techniques for cerumen removal. Geriatrics 2000;55:80, 83-6.

7) Burton M, Dorée CJ. Ear drops for the removal of ear wax. Cochrane Database Syst Rev 2003;(3):CD004400.

8) Meador JA. Cerumen impaction in the elderly. J Gerontol Nurs 1995; 21:43-5.

9) Lewis-Cullinan C, Janken JK. Effect of cerumen removal on the hearing ability of geriatric patients. J Adv Nurs 1990;15:594-600.

10) Pothier DD, Hall C, Gillett S. A comparison of endoscopic and microscopic removal of wax: a randomised clinical trial. Clin Otolaryngol 2006;31:375-80.

11) Wilson PL, Roeser RJ. Cerumen management: professional issues and techniques. J Am Acad Audiol 1997;8:421-30. 